\section{A latter day green Penguin}

\author{
John A. Campbell
}

Hermes and the Golden Thinking Machine. By Alexander Tzonis. MIT Press: 1990. Pp. 284. \$19.95, £14.95.

ARTIFICIAL intelligence (AI) has something for everybody: practitioners, scientific observers from other subjects, people with high and low literary-artistic tastes, and ordinary citizens. It is therefore surprising that there have been rather few tries at writing the Great AI Novel. Most of the existing efforts are squarely in the science-fiction tradition. Some are fun, but even these rely on vague or over-imaginative impressions of what real AI research is about, and hence what are its likely consequences in possible future worlds. Perhaps the secret of eventual success is to be indirect and allusive, not to tackle AI head-on or to put it deliberately in the centre of the stage, and not to take the enterprise too seriously. These conditions are entirely true of my personal favourite in the not-quite-AI class: The Tin Men, by Michael Frayn.

Superficially Hermes and the Golden Thinking Machine is an AI novel, with a criminal plot. Turned inside out, it looks more like a whodunit which would have been perfectly at home in the Penguin greencovered paperback crime series of the $1940 \mathrm{~s}$, with intellectual additions. In terms of $\mathrm{AI}$, it gets a high rating for allusions, an adequate passing grade for suitable lack of seriousness, but only a 'pass if pressed' mark for confrontation. Tackle AI it certainly does, but it brings to mind the story of the Welsh full-back defending himself for losing a rugby game in the last minute by failing to stop one Fotherington-Smith in the English team from scoring a try. "I started to tackle him", he said, "But then Fotherington went one way, Smith went the other, and I tackled the bloody hyphen".

The idea that the main feature of communication (non-communication?) is the encrypting and decrypting of messages is currently fashionable in literary circles where deconstruction is a key word; indeed, some university departments have made an entire industry out of it. In principle depart-

\section{New in paperback}

The Causes of Evolution by J. B. S. Haldane - a classic of evolutionary theory - has just been republished by Princeton University Press with a new afterword by Egbert G. Leigh Jr. Price is $\$ 7.95, £ 4$

From Mandarin comes The Driving Force: Food in Evolution and the Future by Michae Crawford and David Marsh who challenge the idea of survival of the fittest and argue that evolution is a process of cause and effect with nutrition playing a determinant role. Price is £5.99. ments of archaeology are ripe for industrial takeovers, because decription of real or involuntary messages from extinct societies must be an even more distinguished branch of the fashion. Hermes, the book's hero, makes the author's argument for a merger by embodying it: he is a professor of archaeology and AI, who operates in both modes at once.

The idea is fine and deserves development, particularly if combined with some of the most recent preoccupations of $\mathrm{Al}$ research (such as the structure and use of explanation, and the aspects of knowledge representation that are needed to support it) and with insights from philosophers like $\mathbf{R}$. G. Collingwood who have thought about it without the constraints of fashion. What we get instead is an undeveloped version: raw, but the taste is still agreeably exotic.

This is the Fotherington of the book. The Smith is the treatment of technical examples of AI that turn up from time to time - or, at least, introductory textbook examples that were fresh in the mid-1970s - to add a little verisimilitude. A reader does not have to be an AI specialist to suspect that Fotherington and Smith are so different that they can scarcely share the same hyphen. This is unfortunate, because a more up-to-date sample of AI would have given the means for making the two fit together much more convincingly.

But too much highbrow analysis is probably unfair to the author. The book is best read as a latter-day green Penguin. In style and content it would have been a respectable

\section{Long-term study}

\section{T.C. Whitmore}

Four Neotropical Rain Forests. Edited by Alwyn H. Gentry. Yale University Press: 1990. Pp. 627. £42.50, \$66.50.

THIRTY-four scientists have contributed to Four Neotropical Rain Forests. It describes the four places in the New World tropical rain forests which have seen the greatest concentration of research by US biologists of many different disciplines. All four sites have therefore become very familiar in name to tropical biologists. The oldest is Barro Colorado Island (BCI). Panama, where work began 65 years ago when the island was created during the construction of the Panama canal. Following in age sequence are $\mathrm{La}$ Selva, Costa Rica, where research began in 1969, Manu in the Peruvian Amazon (1969/ $70)$ and the Minimum Critical Size of Ecosystems (MCSE) project area $80 \mathrm{~km}$ north of Manaus in Brazil (1979). First the sites themselves are described, then follow sections on floristics, birds, mammals, reptiles and amphibians and forest dynamics. In every section there is a chapter for each site and a concluding chapter of comparison and synthesis. Unfortunately, for MCSE floris- member of that series. The plot is a straightforward romp through modern Greece with a dash of New England as various ambiguous characters strike structuralist and even post-structuralist attitudes and bump each other off in pursuit of the Golden Thinking Machine, a valuable archaeological object. The author is generous with his material, and neglects the experienced crime writer's principle of economy: never introduce any novel piece of data without exploiting it later. For example, the obvious potential for the Machine to prop up the philosophical and message-encryption end of the plot is given only perfunctory attention. Nevertheless, the book is a good enough combined criminal and technical read that one should not be too pedantic about rules of genre.

Despite publication by MIT Press, the main technical interest is probably not $\mathrm{AI}$. As a pure AI frolic, it moves in heavy boots. A more sporting question is whether or not it was written to send up the structuralists and their still more modern friends. It stands either that interpretation or viewing as an accidental send-up by an author, using old AI ideas as tools, who has never deconstructed a text in his life. Either way, it works. A book that can be treated as both a detective story and a reflection of what some of our faculty of arts colleagues are up to is well worth consideration for one's next free long weekend.

John A. Campbell is in the Department of Computer Science, University College London, Gower Street, London WC1E 6BT, UK.

tics a different site $80 \mathrm{~km}$ away is described. For the subject covered, the book gives a summary of the state of knowledge, which is inevitably uneven, and this affects the synthesis chapters.

Much stronger editorial intervention would have been useful, to cut out, for example, considerable repetition of site description and climate, and to provide a complete set of maps to show the outsider where the sites are and what they are like. The suggestion is made in many chapters that species richness is related to productivity and that in turn to soil fertility, but no data are presented and few references given to work to investigate the validity of such a speculation.

The book is best regarded as an introduction to these four much mentioned sites and to the work done so far on the subjects chosen for coverage. For these it provides a useful overview and a way into the scattered research literature, which however needs to be consulted for more critical discussion and evaluation of the data.

The book strongly demonstrates the value of long-term studies, and the important synergy sometimes achieved where different facies of highly complex rain forest ecosystems are studies at the same location. $\square$ T. C. Whitmore is in the Department of Geography, Cambridge University, Downing Place, Cambridge CB2 3EN. UK. 